\title{
A Fast-Response Sliding-Mode Controller for Boost-Type Converters With a Wide Range of Operating Conditions
}

\author{
Siew-Chong Tan, Member, IEEE, Y. M. Lai, Member, IEEE, Chi K. Tse, Fellow, IEEE, \\ Luis Martínez-Salamero, Senior Member, IEEE, and Chi-Kin Wu
}

\begin{abstract}
This paper proposes a fast-response sliding-mode controller for controlling boost-type converters requiring a fast dynamical response over a wide range of operating conditions. The various aspects of the controller, which include the method of generating the reference-current profile, the choice of sliding surface, the existence and stability properties, and the selection of the control parameters, are discussed. Experimental results are presented to validate the theoretical design and to illustrate the strength of the proposed controller. It is demonstrated that, with the proposed controller, the boost converter has a faster response and a lower voltage overshoot over a wide range of operating conditions as compared to that under the widely used peak current-mode controller. Moreover, it is easily realized with simple analog circuitries.
\end{abstract}

Index Terms-Boost converter, current mode, nonlinear controller, pulsewidth modulation (PWM), sliding-mode (SM) control, voltage mode.

\section{INTRODUCTION}

B OOST-TYPE converters operating in the continuousconduction mode (CCM) inherit the right-half-plane-zero (RHPZ) characteristic in their duty-cycle-to-output-voltage transfer functions [1]. This typically makes the dynamic response of the system sluggish, particularly when the mode of control is based solely on controlling the output voltage, i.e., voltage-mode control [1]. The presence of the RHPZ complicates the design and, concurrently, limits the bandwidth of the compensation network in the voltage-mode controller [2]. This is true for both linear and nonlinear types of voltage controllers.

A common solution in achieving fast dynamical response in RHPZ converter systems is to employ the current-mode control [3]. However, being a type of semilinear control methodology, the current-mode control does not support converter applications over a very wide range of operating conditions. Dynamic responses with long settling times and large overshoots that can easily exceed the specification of the targeted application are

Manuscript received December 4, 2006; revised July 10, 2007. An earlier version of this paper was presented at the 2006 IEEE Power Electronics Specialists Conference, Jeju, Korea, June 18-22.

S.-C. Tan, Y. M. Lai, C. K. Tse, and C.-K. Wu are with the Department of Electronic and Information Engineering, Hong Kong Polytechnic University, Kowloon, Hong Kong (e-mail: ensctan@polyu.edu.hk; enymlai@ polyu.edu.hk; encktse@polyu.edu.hk).

L. Martínez-Salamero is with the Departamento de Ingeniería Eléctrónica, Eléctrica y Automática, Escuela Técnica Superior de Ingeniería, Universidad Rovira i Virgili, 43005 Taragona, Spain.

Digital Object Identifier 10.1109/TIE.2007.905969 experienced when the operating conditions deviate too far from the desired points. This has spurred numerous investigations into the possible application of various types of nonlinear controllers on power converters, all with the same objective of improving their controllability and performances for large operating ranges [4]-[21]. Despite their unique advantages, most of the controllers proposed above are impractical for power converters-either requiring complicated control circuitries [4]-[12], being variable-frequency controllers [13]-[20], or having a slow dynamical response [21].

In view of this, we propose in this paper a fixed-frequency sliding-mode (SM) current controller, which is based on an indirect SM control technique and is implemented in pulsewidthmodulation (PWM) form. This controller can offer good large-signal control performances with fast dynamical responses when applied to the boost converters. To provide a complete exposition of this controller, various theoretical and practical aspects of the controller are discussed. A comparison of the general aspects of the performances and properties between the proposed controller and various PWM controllers is also provided. Experimental results are presented to validate the theoretical design and to illustrate the strength of the proposed controller in wide operating conditions.

The main objective of proposing such a nonlinear controller is to provide the control support for boost-type converters which require 1) wide operating conditions that cannot be satisfactorily controlled by conventional PWM current-mode controller and 2) fast response that cannot be met by other SM or nonlinear voltage type of controllers. The salient features of the proposed controller can be summarized as follows:

1) fast dynamical responses comparable to conventional current-mode controllers;

2) inherent robust features of SM control, but operating at a fixed frequency;

3) stable over a wide range of operating conditions;

4) small variation of settling time over a wide range of operating conditions;

5) relatively low voltage overshoots (as compared to currentmode controllers) under large step changes over a wide range of operating conditions.

However, it must be stressed that the advantage of the proposed controller comes with a price of inheriting a slightly more complicated circuit architecture than conventional schemes and also requiring a current sensor in its output-capacitor path. 
This paper aims to present the necessary theoretical background and implementational details that enable the proposed controller to be readily adopted for industrial applications. We also provide details of the various aspects of the controller design and some evaluation of the control performance.

\section{General Comparison of Proposed}

SM-CONTROLLER IMPLEMENTATION WITH TRADITIONAL SM-CONTROLLER IMPLEMENTATION

The traditional implementation of SM controllers is based on hysteresis-modulation (HM) (or delta modulation), i.e., they require a bang-bang type of controller to perform the switching control [14], [15], [20], [22]-[27]. Hence, they inherit the typical disadvantages of having variable switching-frequency operation and being highly control sensitive to noise. To achieve constant frequency operation, possible solutions are either to incorporate constant timer circuits, adopt adaptive hysteresis band control, or inject a synchronizing signal into the hysteric controller. Of course, these solutions require additional components and are less suited for low-cost voltage-conversion applications.

The proposed SM controller is developed using the PWM technique (i.e., duty-cycle control) instead of the traditionally adopted HM technique [14], [21], [28]-[36]. The fundamental difference between the two types of controllers is that the former uses a pulsewidth modulator to construct the control signal required for SM operation, while the latter uses a hysteresis comparator for constructing the same control signal. The advantage of using the PWM technique is that, by fixing the frequency of its ramp signal, the frequency of the output switching signal will be constant, regardless of how the duty cycle varies with the variation of the control signal. Thus, by employing this modulation technique in SM control, a fixed-frequency PWM-based SM controller that retains the SM control properties of traditional SM controller can be obtained. The advantages of using this technique to achieve constant frequency are that it does not need additional hardware circuitries, since the switching function is performed by the PWM modulator, and that, its transient response is not deteriorated. However, the implementation is nontrivial in order to preserve the original SM control law, particularly if both the current and voltage state variables are involved. This is because the indirect implementation of the original SM control law may result in unexpected complications in the signal computation. The controller may end up having to involve state variables that are difficult or impossible to sense or, otherwise, requiring very complicated computations to predict. In this sense, the approach is not always feasible for some SM-controller types.

\section{Proposed SM Current Controller}

The proposed SM current controller employs both the outputvoltage error and the inductor-current error as the controlled state variables. The adoption of the output-voltage error as a state variable allows the output voltage to be accurately regulated, whereas the inductor-current error allows the inductor current to follow closely the desired reference inductor current.
As in the conventional current-mode controller, the monitoring and tracking of the inductor-current reference is the key in having a fast dynamical response in RHPZ converter systems.

\section{A. Generating a Suitable Reference-Current Profile}

Similar to the conventional PWM current-mode control, the instantaneous reference-inductor-current profile $i_{\text {ref }}$ in the proposed controller is generated using the amplified output-voltage error, i.e.,

$$
i_{\text {ref }}=K\left[V_{\text {ref }}-\beta v_{\mathrm{o}}\right]
$$

where $V_{\text {ref }}$ and $v_{\mathrm{o}}$ denote the reference and instantaneous output voltages, respectively, $\beta$ denotes the feedback-network ratio, and $K$ is the amplified gain of the voltage error. A large value of $K$ is chosen for improved dynamic response and for minimizing the steady-state voltage error in the system, of which, at steady-state operation, the reference-current profile (i.e., the amplified steady-state voltage error) will be equivalent to the steady-state inductor current, i.e., $I_{\text {ref(ss) }}=I_{L(\mathrm{ss})}=K\left[V_{\text {ref }}-\right.$ $\left.\beta V_{\mathrm{o}(\mathrm{ss})}\right]$. This would mean that $V_{\mathrm{ref}}-\beta V_{\mathrm{o}(\mathrm{ss})} \approx 0$ and not exactly zero. In such circumstance, the use of an additional integral action to generate the reference-current profile is optional. It has insignificant influence on the steady-state regulation and can be ignored to simplify circuit implementation. Note that the main voltage regulation is performed by the SM control function, which has an integral control action to alleviate the output-voltage-regulation error. On the other hand, in the case where a very tight regulation is required, the integral term can be included to give the reference current as $i_{\text {ref }}=K_{\mathrm{i}} \int\left[V_{\text {ref }}-\right.$ $\left.\beta v_{\mathrm{o}}\right] d t+K_{\mathrm{p}}\left[V_{\text {ref }}-\beta v_{\mathrm{o}}\right]$. The same mathematical treatment, as provided in the following sections, can be used to derive such a controller. For this paper, the generation of reference current will be based on (1).

\section{B. Proposed Sliding Surface}

With a switching function $u=1 / 2(1+\operatorname{sign}(S))$, where $u$ represents the logic state of power switch $S_{\mathrm{W}}$, the sliding surface of the proposed controller is chosen to be a linear combination of three state variables, i.e.,

$$
S=\alpha_{1} x_{1}+\alpha_{2} x_{2}+\alpha_{3} x_{3}
$$

where $\alpha_{1}, \alpha_{2}$, and $\alpha_{3}$ represents the sliding coefficients. Here, the adopted controlled state variables are the current error $x_{1}$, the voltage error $x_{2}$, and the integral of the current and the voltage errors $x_{3}$, which are expressed as

$$
\left\{\begin{aligned}
x_{1} & =i_{\text {ref }}-i_{L} \\
x_{2} & =V_{\text {ref }}-\beta v_{\mathrm{o}} \\
x_{3} & =\int\left[x_{1}+x_{2}\right] d t \\
& =\int\left(i_{\text {ref }}-i_{L}\right) d t+\int\left(V_{\text {ref }}-\beta v_{\mathrm{o}}\right) d t
\end{aligned}\right.
$$

where $i_{L}$ denotes the instantaneous inductor current. Ideally, at an infinitely high switching frequency, only the controlled variables $x_{1}$ and $x_{2}$ are required in the SM current controller to ensure that both the output voltage and inductor current are 
regulated to follow exactly their references, i.e., $v_{\mathrm{o}}=V_{\text {ref }}$ and $i_{L}=i_{\text {ref. }}$. However, in the case of finite-frequency or fixedfrequency SM controllers, the control is imperfect. Steady-state errors exist in both the output-voltage error and the inductorcurrent error, such that $v_{\mathrm{o}} \neq V_{\text {ref }}$ and $i_{L} \neq i_{\text {ref }}$. Therefore, an integral term of these errors $x_{3}$ has been introduced into the SM current controller as an additional controlled state variable to reduce these steady-state errors. This is commonly known as integral SM control [37], and its application in power converters has captured some recent interests [38]-[40].

\section{Dynamical Model of Proposed Controller/Converter System and Its Equivalent Control}

The substitution of the boost converter's behavioral models under CCM into the time differentiation of (3) gives the dynamical model of the proposed system as

$$
\left\{\begin{aligned}
\dot{x_{1}} & =\frac{d\left[i_{\mathrm{ref}}-i_{L}\right]}{d t}=-\frac{\beta K}{C} i_{C}-\frac{v_{\mathrm{i}}-\bar{u} v_{\mathrm{o}}}{L} \\
\dot{x_{2}} & =\frac{d\left[V_{\mathrm{ref}}-\beta v_{\mathrm{o}}\right]}{d t}=-\frac{\beta}{C} i_{C} \\
\dot{x_{3}} & =x_{1}+x_{2}=\left(i_{\mathrm{ref}}-i_{L}\right)+\left(V_{\mathrm{ref}}-\beta v_{\mathrm{o}}\right) \\
& =(K+1)\left[V_{\mathrm{ref}}-\beta v_{\mathrm{o}}\right]-i_{L}
\end{aligned}\right.
$$

where $\bar{u}=1-u$ is the inverse logic of $u, v_{\mathrm{i}}$ denotes the instantaneous input voltage, $i_{C}$ denotes the instantaneous capacitor current, and $C$ and $L$ denote the capacitance and inductance of the converters, respectively. In addition, with respect to the converter, $r_{\mathrm{L}}$ and $i_{r}$ are defined as the instantaneous load resistance and load current.

The equivalent-control signal of the proposed SM current controller, when applied to the boost converter, is obtained by solving $d S / d t=\alpha_{1} \dot{x_{1}}+\alpha_{2} \dot{x_{2}}+\alpha_{3} \dot{x_{3}}=0$ [37], which gives

$$
u_{\mathrm{eq}}=1-\frac{K_{2}}{v_{\mathrm{o}}} i_{C}-\frac{v_{\mathrm{i}}}{v_{\mathrm{o}}}+\frac{K_{1}}{v_{\mathrm{o}}}\left[V_{\mathrm{ref}}-\beta v_{\mathrm{o}}\right]-\frac{K_{3}}{v_{\mathrm{o}}} i_{L}
$$

where

$$
K_{1}=\frac{\alpha_{3}}{\alpha_{1}} L(K+1) ; \quad K_{2}=\frac{\beta L}{C}\left(K+\frac{\alpha_{2}}{\alpha_{1}}\right) ; \quad K_{3}=\frac{\alpha_{3}}{\alpha_{1}} L
$$

are the fixed gain parameters in the proposed controller, and $u_{\mathrm{eq}}$ is continuous and bounded by zero and one (for more understanding of equivalent control, readers are referred to [37]). Note that (5) can be expressed alternatively in terms of the original controlled state variables $x_{1}$ and $x_{2}$, i.e.,

$$
u_{\mathrm{eq}}=1-\frac{K_{2} \frac{v_{\mathrm{o}}}{r_{\mathrm{L}}}-v_{\mathrm{i}}+K_{3}\left[V_{\mathrm{ref}}-\beta v_{\mathrm{o}}\right]-K_{3}\left(i_{\mathrm{ref}}-i_{L}\right)}{K_{2} i_{L}-v_{\mathrm{o}}} .
$$

However, this will result in a complex form of equivalentcontrol signal $u_{\text {eq }}$, which complicates the implementation of the controller. The use of instantaneous state variables $i_{C}$ and $i_{L}$ in the expression minimizes such complexity, as evidenced in the preceding section. It should also be mentioned that, even though different forms of equivalent-control signal equation with respect to their chosen state variables can be obtained, they

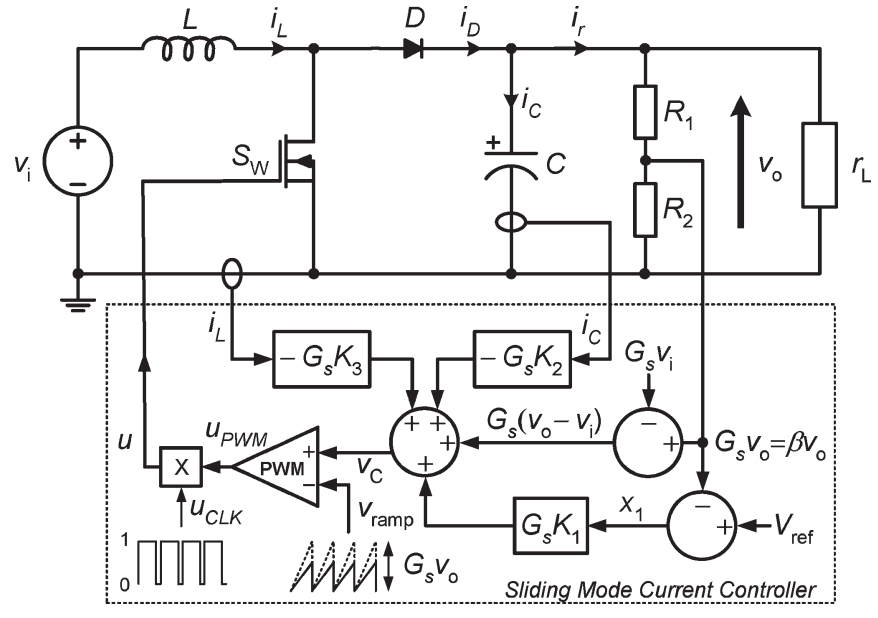

Fig. 1. Proposed SM current controller for boost converters.

fundamentally give the same solution, i.e., $u_{\text {eq }}=f_{1}\left(x_{1}, x_{2}\right)=$ $f_{2}\left(i_{C}, i_{L}\right)$.

\section{Architecture of Proposed Controller}

The proposed SM current controller, which operates at a fixed frequency, is implemented through a pulsewidth modulator by adopting a set of control laws derived using the indirect SM control technique [35]. This makes it a type of PWM-based SM controller. The controller is derived from the sliding surface (2) and, then, equating $u_{\mathrm{eq}}=d$, where $d$ is the duty-cycle control signal of a PWM controller [35]. This procedure gives the PWM control architecture that reproduces the static and dynamic behavior of the original SM controller but operates like a PWM controller. The equations of the control law comprise a control signal $v_{\mathrm{c}}$ and a ramp signal $\hat{v}_{\text {ramp }}$, which, in the proposed controller, inherits the expression

$$
\left\{\begin{array}{c}
v_{\mathrm{c}}=G_{s} K_{1}\left[V_{\mathrm{ref}}-\beta v_{\mathrm{o}}\right]-G_{s} K_{2} i_{C} \\
\quad-G_{s} K_{3} i_{L}+G_{s}\left[v_{\mathrm{o}}-v_{\mathrm{i}}\right] \\
\hat{v}_{\text {ramp }}=G_{s} v_{\mathrm{o}}
\end{array} .\right.
$$

Here, a factor of $0<G_{s}<1$ has been intentionally introduced for down scaling the equation to a practical magnitude level that conforms to the chip level's voltage standard of implementation. Moreover, recalling that the boost-type converter cannot operate with a switching signal $u$ that has a duty cycle $d=1$, a small protective circuitry is required to ensure that the duty cycle of the controller's output is always $d<1$. In the proposed controller, this is satisfied by multiplying the logic state $u_{\mathrm{PWM}}$ of the pulsewidth modulator with the logic state $u_{\mathrm{CLK}}$ of an impulse generator using a logic AND operator (see Fig. 1).

Fig. 1 shows an overview of the proposed SM current controller for the boost converters. The design of the controller is based on (8) and the assumption $\beta=G_{s}$. It should be noted that, as in the fixed-frequency SM voltage controller proposed in [21], a ramp generator that varies its peak voltage with the change of output voltage is required for the nonlinear compensation. However, unlike the SM voltage controller, the proposed controller need not take into consideration the input voltage in its ramp voltage generation. This results in a simpler 
ramp-generator circuitry in the latter than the former. It is also worth noting that two current sensors are required in the implementation of the proposed controller. This is the main drawback of using this controller as compared to the SM voltage controller, which requires only the sensing of the capacitor current. However, the additional current sensing required on the inductor current is actually the main component constituting to a faster responding RHPZ converter system.

\section{E. Existence Condition}

For SM operation to occur in this controller, the three necessary conditions of SM, namely, the hitting, existence, and stability conditions, have to be abided. So far, the hitting condition has been satisfied by the appropriate choice of the switching function. ${ }^{1}$ As for the existence condition, it can be obtained by inspecting the local reachability condition $\lim _{S \rightarrow 0} S \cdot(d S / d t)<0$, which, with the substitutions of (2) and its time derivative, gives

$$
\left\{\begin{array}{c}
\alpha_{1}\left[-\frac{\beta K}{C} i_{C}-\frac{v_{\mathrm{i}}}{L}\right]-\alpha_{2} \frac{\beta}{C} i_{C} \\
\quad+\alpha_{3}\left((K+1)\left[V_{\mathrm{ref}}-\beta v_{\mathrm{o}}\right]-i_{L}\right)<0 \\
\alpha_{1}\left[-\frac{\beta K}{C} i_{C}-\frac{v_{\mathrm{i}}-v_{\mathrm{o}}}{L}\right]-\alpha_{2} \frac{\beta}{C} i_{C} \\
\quad+\alpha_{3}\left((K+1)\left[V_{\mathrm{ref}}-\beta v_{\mathrm{o}}\right]-i_{L}\right)>0
\end{array} .\right.
$$

Assuming that the controller is designed with a static sliding surface to meet the existence conditions for steady-state operations (equilibrium point) [35]-[42] and with the consideration of (6), then (9) can be simplified as

$$
\left\{\begin{array}{c}
0<v_{\mathrm{i}(\min )}-K_{1}\left[V_{\mathrm{ref}}-\beta v_{\mathrm{o}(\mathrm{SS})}\right] \\
+K_{2} i_{C(\min )}+K_{3} i_{L(\max )} \\
v_{\mathrm{i}(\max )}-K_{1}\left[V_{\mathrm{ref}}-\beta v_{\mathrm{o}(\mathrm{SS})}\right] \\
+K_{2} i_{C(\max )}+K_{3} i_{L(\min )}<v_{\mathrm{o}(\mathrm{SS})}
\end{array}\right.
$$

where $v_{\mathrm{i}(\max )}$ and $v_{\mathrm{i}(\min )}$ denotes the maximum and minimum input voltages, respectively, $v_{\mathrm{o}(\mathrm{SS})}$ denotes the expected steadystate output voltage which is basically a dc parameter of a small error from the desired reference voltage $V_{\text {ref }}$, and $i_{L(\max )}$, $i_{L(\min )}, i_{C(\max )}$, and $i_{C(\min )}$ are, respectively, the maximum and minimum inductor and capacitor currents when the converter is operating at full-load condition. Fig. 2 illustrates the physical representation of these parameters.

Finally, the selection of the controller's gain parameters $K_{1}$, $K_{2}$, and $K_{3}$ must comply with the set of inequalities in (10). This assures the existence of the SM operation at least in the small region of the origin for all operating conditions up to full load.

\section{F. Stability Condition}

Unlike in SM voltage controllers where the selection of the sliding coefficients (control gains) to satisfy the stability condition is automatically performed by designing the system

\footnotetext{
${ }^{1}$ Satisfaction of the hitting condition assures that, regardless of the initial condition, the state trajectory of the system will always be directed toward the sliding surface.
}

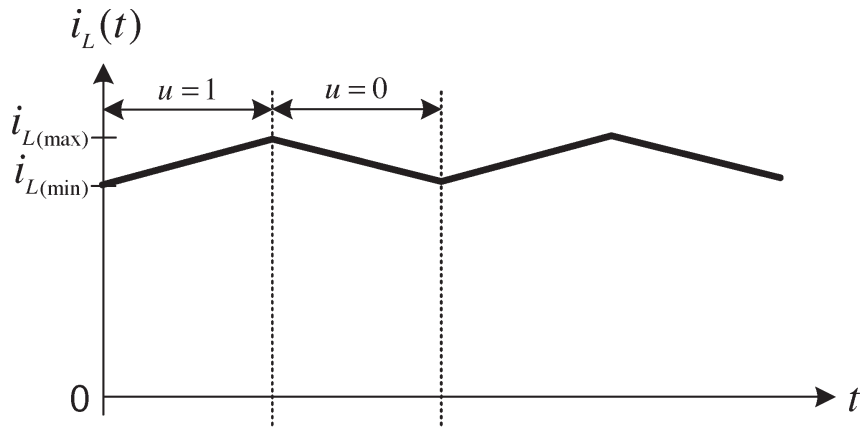

(a)

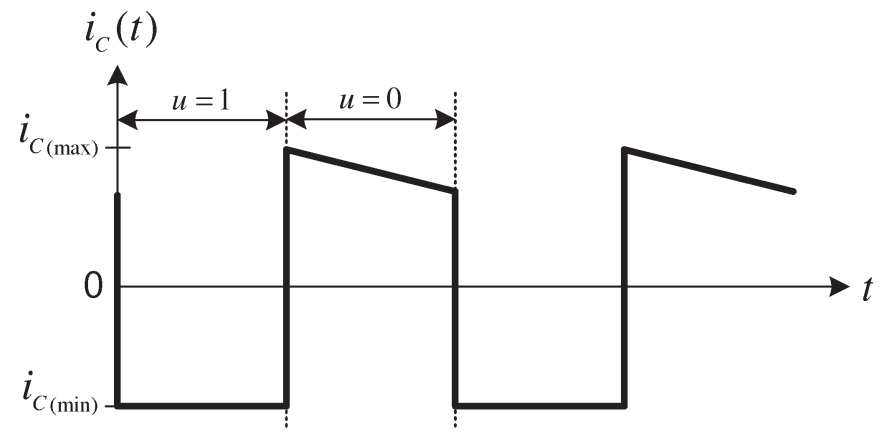

(b)

Fig. 2. Current waveforms of boost converters. (a) Inductor-current waveform. (b) Capacitor-current waveform.

for some desired dynamic properties [21], [35], ${ }^{2}$ the same approach cannot be adopted in designing the proposed SM current controller. This is because the motion equation (derived from $S=0$ ) of the proposed controller, which composes both the current and voltage state variables, is highly nonlinear and cannot be easily solved by analytical method. A different approach based on the equivalent-control method is adopted [37]. This is to first derive for the ideal sliding dynamics of the system and, then, doing an analysis on its equilibrium point, which finally allows the stability condition to be obtained [42], [43].

1) Ideal Sliding Dynamics: The replacement of $\bar{u}$ by $\bar{u}_{\mathrm{eq}}$ (so-called equivalent-control method) into the original boost converter's description under CCM operation converts the discontinuous system into an ideal SM continuous system

$$
\left\{\begin{array}{l}
\frac{d i_{L}}{d t}=\frac{v_{\mathrm{i}}}{L}-\frac{v_{\mathrm{o}}}{L} \bar{u}_{\mathrm{eq}} \\
\frac{d v_{\mathrm{o}}}{d t}=\frac{i_{L}}{C} \bar{u}_{\mathrm{eq}}-\frac{v_{\mathrm{o}}}{r_{\mathrm{L}} C}
\end{array} .\right.
$$

Then, the substitution of (7) into (11) gives

$$
\left\{\begin{aligned}
\frac{d i_{L}}{d t} & =\frac{v_{\mathrm{i}}}{L}-\frac{v_{\mathrm{o}}}{L_{\mathrm{O}}} \frac{K_{2} \frac{v_{\mathrm{o}}}{r_{\mathrm{L}}}-v_{\mathrm{i}}+K_{3}\left[V_{\mathrm{ref}}-\beta v_{\mathrm{o}}\right]-K_{3}\left(i_{\mathrm{ref}}-i_{L}\right)}{K_{2} i_{L}-v_{\mathrm{o}}} \\
\frac{d v_{\mathrm{o}}}{d t} & =\frac{i_{L}}{C} \frac{K_{2} \frac{v_{\mathrm{o}}}{r_{\mathrm{L}}}-v_{\mathrm{i}}+K_{3}\left[V_{\mathrm{ref}}-\beta v_{\mathrm{o}}\right]-K_{3}\left(i_{\mathrm{ref}}-i_{L}\right)}{K_{2} i_{L}-v_{\mathrm{o}}}-\frac{v_{\mathrm{o}}}{r_{\mathrm{L}} C}
\end{aligned}\right.
$$

which represents the ideal sliding dynamics of the SM-currentcontrolled boost converter.

2) Equilibrium-Point Analysis: Assume that there exists a stable equilibrium point on the sliding surface on which the

\footnotetext{
${ }^{2}$ Satisfaction of the stability condition ensures that the state trajectory of the system under SM operation will always reach a stable equilibrium point.
} 


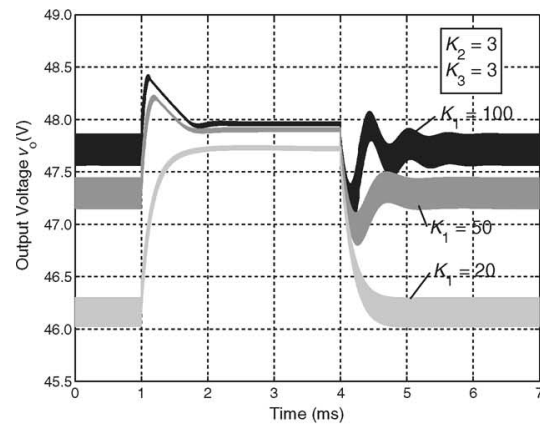

(a)

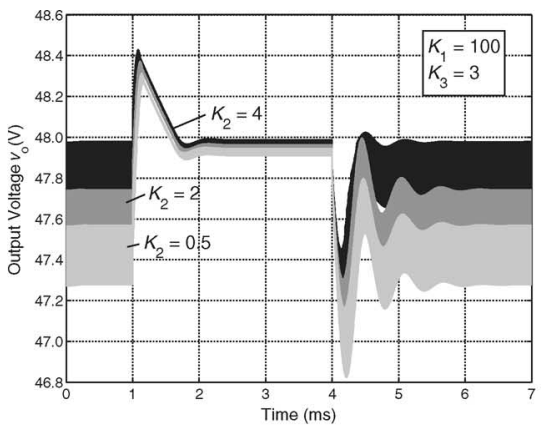

(b)

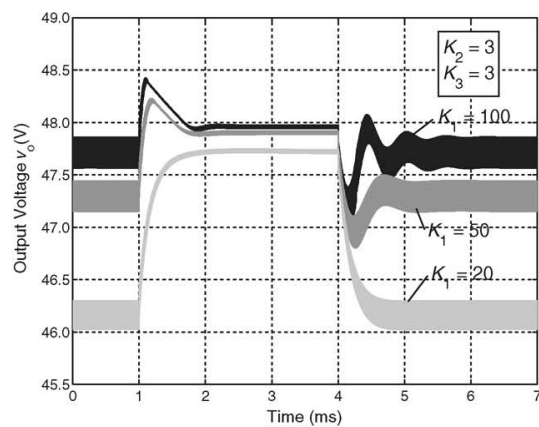

(c)

Fig. 3. Simulated waveforms of the output voltage $v_{\mathrm{o}}$ of a boost converter under the proposed SM current controller at various control-gain settings. (a) Different $K_{1}$ settings. (b) Different $K_{2}$ settings. (c) Different $K_{3}$ settings.

ideal sliding dynamics eventually settled. At this point of equilibrium (steady state), there will not be any change in the system's dynamics if there is no input or loading disturbance, i.e., $d i_{L} / d t=d v_{\mathrm{o}} / d t=0$. Then, the state equations in (12) can be equated to give

$$
I_{L}=\frac{V_{\mathrm{o}}^{2}}{V_{\mathrm{i}} R_{\mathrm{L}}}
$$

where $I_{L}, V_{\mathrm{o}}, V_{\mathrm{i}}$, and $R_{\mathrm{L}}$ represents the inductor current, output voltage, input voltage, and load resistance at steady-state equilibrium, respectively.

3) Linearization of Ideal Sliding Dynamics: Next, the linearization of the ideal sliding dynamics around the equilibrium point transforms (12) into

$$
\left\{\begin{array}{l}
\frac{d \tilde{i}_{L}}{d t}=a_{11} \tilde{i}_{L}+a_{12} \tilde{v}_{\mathrm{o}} \\
\frac{d \tilde{v}_{\mathrm{o}}}{d t}=a_{21} \tilde{i}_{L}+a_{22} \tilde{v}_{\mathrm{o}}
\end{array}\right.
$$

where

$$
\left\{\begin{array}{l}
a_{11}=\frac{K_{3} V_{\mathrm{i}} R_{\mathrm{L}}}{K_{2} L V_{\mathrm{o}}-L V_{\mathrm{i}} R_{\mathrm{L}}} \\
a_{12}=\frac{K_{1} \beta V_{\mathrm{i}} R_{\mathrm{L}}-2 K_{2} V_{\mathrm{i}}+\frac{V_{\mathrm{i}}^{2} R_{\mathrm{L}}}{V_{\mathrm{o}}}}{K_{2} L V_{\mathrm{o}}-L V_{\mathrm{i}} R_{\mathrm{L}}} \\
a_{21}=\frac{K_{2} V_{\mathrm{i}}-\frac{V_{\mathrm{i}}^{2} R_{\mathrm{L}}}{V_{\mathrm{o}}}-K_{3} V_{\mathrm{o}}}{K_{2} V_{\mathrm{o}} C-C V_{\mathrm{i}} R_{\mathrm{L}}} \\
a_{22}=\frac{\frac{K_{2} V_{\mathrm{o}}}{R_{\mathrm{L}}}-K_{1} \beta V_{\mathrm{o}}}{K_{2} V_{\mathrm{o}} C-C V_{\mathrm{i}} R_{\mathrm{L}}}-\frac{1}{R_{\mathrm{L}} C}
\end{array} .\right.
$$

The derivation is performed with the adoption of the following static equilibrium conditions: $V_{\mathrm{i}}=v_{\mathrm{i}} ; R_{\mathrm{L}}=r_{\mathrm{L}} ; V_{\text {ref }}-\beta V_{\mathrm{o}}=$ 0 ; and $I_{\text {ref }}-I_{L}=0$. Moreover, the assumptions $I_{L} \gg \tilde{i}_{L}$ and $V_{\mathrm{o}} \gg \tilde{v}_{\mathrm{o}}$. The characteristic equation of this linearized system will be given by

$$
s^{2}-\left(a_{11}+a_{22}\right) s+a_{11} a_{22}-a_{12} a_{21}=0 .
$$

The system will be stable if the following conditions are satisfied:

$$
\begin{array}{r}
a_{11}+a_{22}<0 \\
a_{11} a_{22}-a_{12} a_{21}>0 .
\end{array}
$$

For the case of $a_{11}+a_{22}<0$, the condition for stability is

$$
\frac{K_{3} C V_{\mathrm{i}} R_{\mathrm{L}}-K_{1} L \beta V_{\mathrm{o}}+L V_{\mathrm{i}}}{K_{2} V_{\mathrm{o}}-V_{\mathrm{i}} R_{\mathrm{L}}}<0
$$

i.e.,

$$
\left\{\begin{array}{ll}
K_{3} \frac{V_{\mathrm{i}} R_{\mathrm{L}} C}{L \beta V_{\mathrm{o}}}+\frac{V_{\mathrm{i}}}{\beta V_{\mathrm{o}}}<K_{1}, & \text { when } K_{2}>\frac{V_{\mathrm{i}} R_{\mathrm{L}}}{V_{\mathrm{o}}} \\
K_{3} \frac{V_{\mathrm{i}} R_{\mathrm{L}} C}{L \beta V_{\mathrm{o}}}+\frac{V_{\mathrm{i}}}{\beta V_{\mathrm{o}}}>K_{1}, & \text { when } K_{2}<\frac{V_{\mathrm{i}} R_{\mathrm{L}}}{V_{\mathrm{o}}}
\end{array} .\right.
$$

As for the case of $a_{11} a_{22}-a_{12} a_{21}>0$, the condition for stability is

$$
\begin{aligned}
2 K_{3} V_{\mathrm{o}}^{3}\left(K_{2}\right. & \left.-K_{1} \beta R_{\mathrm{L}}\right)+V_{\mathrm{i}} V_{\mathrm{o}}^{2} K_{2}\left(K_{1} \beta R_{\mathrm{L}}-2 K_{2}\right) \\
& +V_{\mathrm{i}}^{2} V_{\mathrm{o}} R_{\mathrm{L}}\left(3 K_{2}-K_{1} \beta R_{\mathrm{L}}\right)-V_{\mathrm{i}}^{3} R_{\mathrm{L}}^{2}>0 .
\end{aligned}
$$

In essence, the existence condition (10) and the stability conditions (19) and (20) form the basis for the selection and design of the control gains of the proposed SM current controller in terms of the converter's specification. Satisfaction of these conditions assures the closed-loop stability of the system.

\section{G. Empirical Approach of Selecting the Sliding Coefficients}

To relief the difficulty of designing the control gains based solely on complying the various conditions, computer simulation and experiments were performed to study the effects of the various control gains on the response of the output voltage. The following observations are made.

1) An increment in $K_{1}$ improves the steady-state regulation but causes the transient response to be more oscillatory with a higher overshoot, thus prolonging the steady-state settling time [see Fig. 3(a)].

2) An increment in $K_{2}$ improves the steady-state regulation and also makes the transient response less oscillatory with a lower overshoot, thus shortening the steady-state settling time [see Fig. 3(b)]. However, the range of adjustable values for $K_{2}$ is very small (limited by the bidirectional capacitor current).

3) A relatively small increment in $K_{3}$ can have a moderate reduction in the oscillation of the transient response and also significant shortening of the steady-state settling time. However, the steady-state regulation is deteriorated [see Fig. 3(c)]. 
TABLE I

COMPARISON OF THE VARIOUS FIXED-FREQUENCY PWM-CONTROL SCHEMES

\begin{tabular}{|c|c|c|c|c|}
\hline Category of Comparison & Voltage Mode & $\begin{array}{c}\text { Peak Current Mode/ } \\
\text { Average Current Mode }\end{array}$ & $\begin{array}{c}\text { Sliding Mode } \\
\text { Voltage Controller }\end{array}$ & $\begin{array}{c}\text { Sliding Mode } \\
\text { Current Controller }\end{array}$ \\
\hline type of control & linear & some nonlinearity & nonlinear & nonlinear \\
\hline compensation design & difficult & moderate/difficult & easy & moderate \\
\hline steady-state line and load regulation & average & good & average & average \\
\hline large-signal dynamic response consistency & poor & average & good & good \\
\hline gain bandwidth in RHPZ converter & low & relatively higher & low & relatively higher \\
\hline number of current sensing & nil & one & one & two \\
\hline noise-to-signal ratio & low & high/moderate & moderate & moderate \\
\hline current protection & external circuit & inherent & external circuit & inherent \\
\hline audiosusceptibility protection & external scheme & inherent & existing & inherent \\
\hline
\end{tabular}

Hence, in accordance to these observations, a heuristic but practical approach in designing the control gains is to first select the highest possible values of $K_{1}$ and $K_{2}$, and an arbitrarily low value of $K_{3}$, without compromising the existence or stability condition for the full-load condition. Then, having the converter operated at the nominal input voltage and the step load changes between the minimum and maximum loading condition, both the values of $K_{1}$ and $K_{3}$ can be up- or down-tuned to fit the converter's performance to the desired profile. As in conventional controllers, such tuning of the control parameters is typically required in the initial prototyping stage to ensure that the converter responses in the desired manner before actual application or mass production. However, an advantage of the SM current controller over a conventional controller is that, once the parameters are decided for the nominal condition, the large-signal property of the SM current controller will ensure a consistent dynamical behavior for all operating conditions, as in the SM voltage controller. This eliminates the need of retuning the parameters to suit other operating conditions, as would be required in conventional controllers.

\section{H. Additional Remarks}

The proposed fixed-frequency SM current controller inherits the other advantages of the controlling current, namely, the overcurrent and audiosusceptibility protection properties. In addition, being a form of nonlinear controller, it is capable of handling large-signal perturbations with excellent consistency in its dynamical responses. In other words, the targeted application of this controller is to provide the control support for RHPZ converters requiring a fast response over a wide range of operating conditions, which cannot be satisfactorily controlled by the conventional current-mode controller. This serves as the main justification for its practical use, although it requires an additional current sensor and also inherits a slightly more complicated circuit architecture than conventional schemes. Table I summarizes the general aspects of the performances and properties between the proposed controller and various PWM controllers.

On the other hand, it is clearly seen from the simulation results that the proposed SM current controller, which uses an integral sliding surface, is capable of reducing the steady-state errors only to a certain satisfactory level. Further suppression of these errors is not possible unless an additional double-
TABLE II

SPECIFICATION OF Boost CONVERTER

\begin{tabular}{|lcc|}
\hline Description & Parameter & Nominal Value \\
\hline Input voltage & $v_{\mathrm{i}}$ & $24 \mathrm{~V}$ \\
Capacitance & $C$ & $230 \mu \mathrm{F}$ \\
Capacitor ESR & $r_{c}$ & $69 \mathrm{~m} \Omega$ \\
Inductance & $L$ & $300 \mu \mathrm{H}$ \\
Inductor resistance & $r_{l}$ & $0.14 \Omega$ \\
Switching frequency & $f_{\mathrm{S}}$ & $200 \mathrm{kHz}$ \\
Minimum load resistance (full load) & $r_{\mathrm{L}(\min )}$ & $24 \Omega$ \\
Maximum load resistance (10\% load) & $r_{\mathrm{L}(\max )}$ & $240 \Omega$ \\
Desired output voltage & $V_{\mathrm{od}}$ & $48 \mathrm{~V}$ \\
\hline
\end{tabular}

integral term of the state variables, i.e., $\int\left(\int\left[x_{1}+x_{2}\right] d t\right) d t$, is introduced into the controller. This is based on the wellknown control understanding that the increased order (pole) of the controller improves the steady-state accuracy of the system.

\section{RESUlTS AND Discussions}

In this section, simulation and experimental results of the proposed SM current controller are provided to validate the theoretical design. ${ }^{3}$ Both the simulation program and the hardware prototype are developed from (8) for 100-W boost converters with specification shown in Table II. The control parameters adopted are $V_{\text {ref }}=6 \mathrm{~V}, G_{s}=\beta=1 / 8, K_{1}=80, K_{2}=3.12$, and $K_{3}=2.67$. They are chosen to comply the design restrictions in (10), (19), and (20) and have been fine tuned to respond to a desired regulation and dynamic response. Fig. 4 shows the full schematic diagram of the experimental prototype, which is constructed using simple analog ICs and operational amplifiers (see also Fig. 1).

\section{A. Regulation Performance}

Fig. 5 shows the steady-state waveforms of the proposed SM-current-controlled boost converter operating at nominal input voltage. The control signal $v_{\mathrm{c}}$ is derived from analog computation of the instantaneous feedback signals $v_{\mathrm{o}}, v_{\mathrm{i}}, i_{L}$, and $i_{C}$ using the expression described in (8). In addition, the peak magnitude of the ramp signal $v_{\text {ramp }}$ is generated to follow

\footnotetext{
${ }^{3}$ The simulation is performed using MATLAB/Simulink. The step size taken for all simulations is $10 \mathrm{~ns}$.
} 


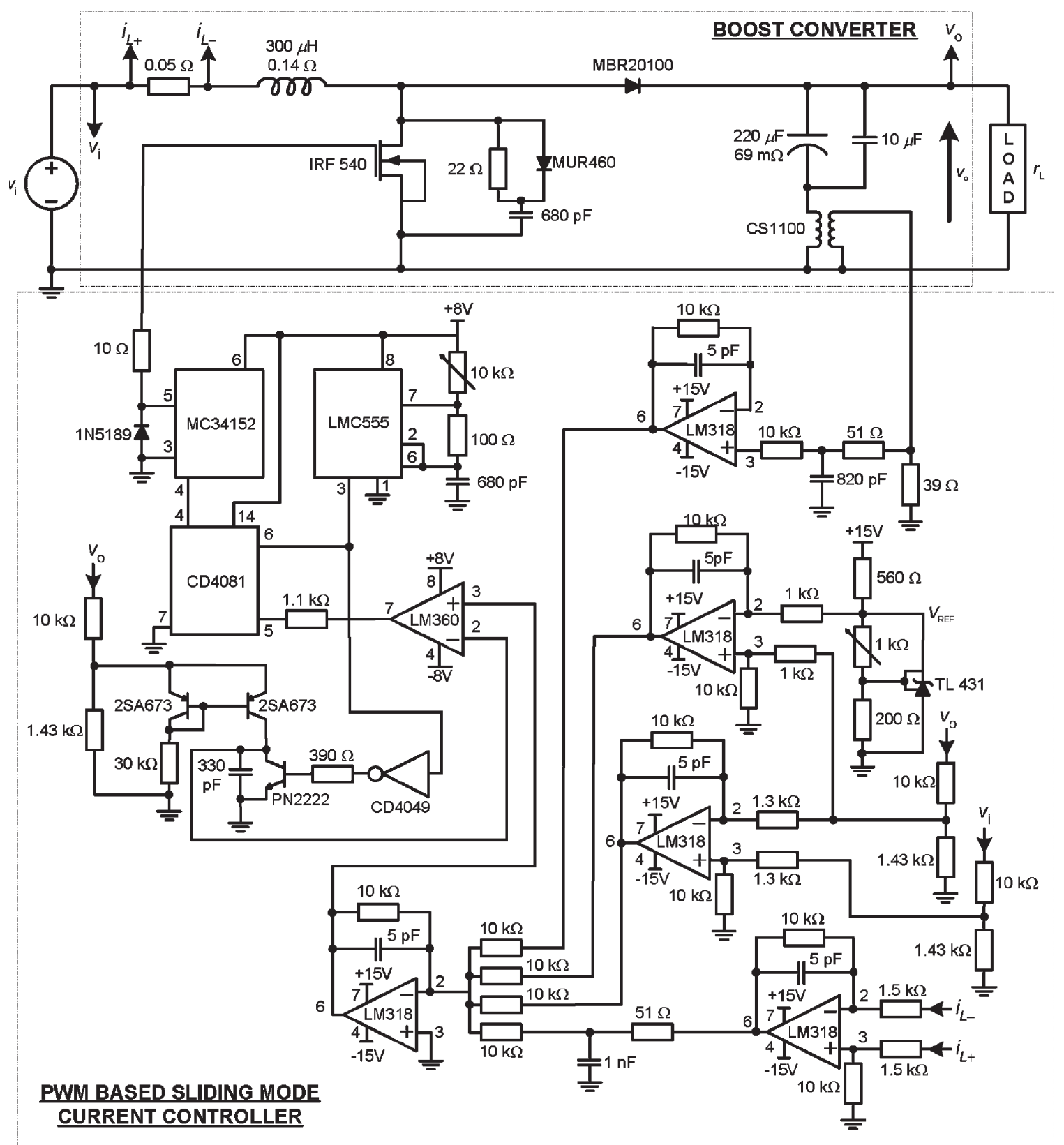

Fig. 4. Full schematic diagram of the proposed SM-current-controlled boost-converter prototype.

$G_{s} v_{\mathrm{O}}$ as in (8). Both $v_{\mathrm{c}}$ and $v_{\mathrm{ramp}}$ are fed into a pulsewidth modulator to generate the gate pulse $u$ for the switching of the boost converter. Except for some ringing noise and a small time delay in the experimentally captured $v_{\mathrm{c}}$ waveforms, the simulation and experimental results are in good agreement with the theoretical prediction. The slight discrepancy is mainly due to the nonideality of practical sensors and analog components, which are not modeled in the simulation program. However, it is worth mentioning that, as in average current-mode control, such ringing noise has much less influence on the generated control pulse than the peak current-mode control.

A tabulation of the data in terms of the load- and lineregulation properties is also given in Tables III and IV respectively. According to Table III, the maximum loadregulation error occurs at $v_{\mathrm{i}}=20 \mathrm{~V}$, with a deviation of $2.38 \%$ from $v_{\mathrm{o} \text { (nominal condition) }}$. Similarly, it can be found from Table IV that the maximum line-regulation error occurs at minimum load $r_{\mathrm{L}}=240 \Omega$, with a deviation of $0.84 \%$ from $v_{\mathrm{O}(\text { nominal condition })}$.

\section{B. Dynamic Performance}

The dynamical property of the proposed controller in handling large-signal disturbances is compared to that of a UC3843 peak current-mode controller. Comparison with the average current-mode controller is redundant in this case since it offers similar dynamic characteristic as that of the peak current-mode controller under large-signal disturbances. Moreover, average current-mode controller is not often adopted in practice. 

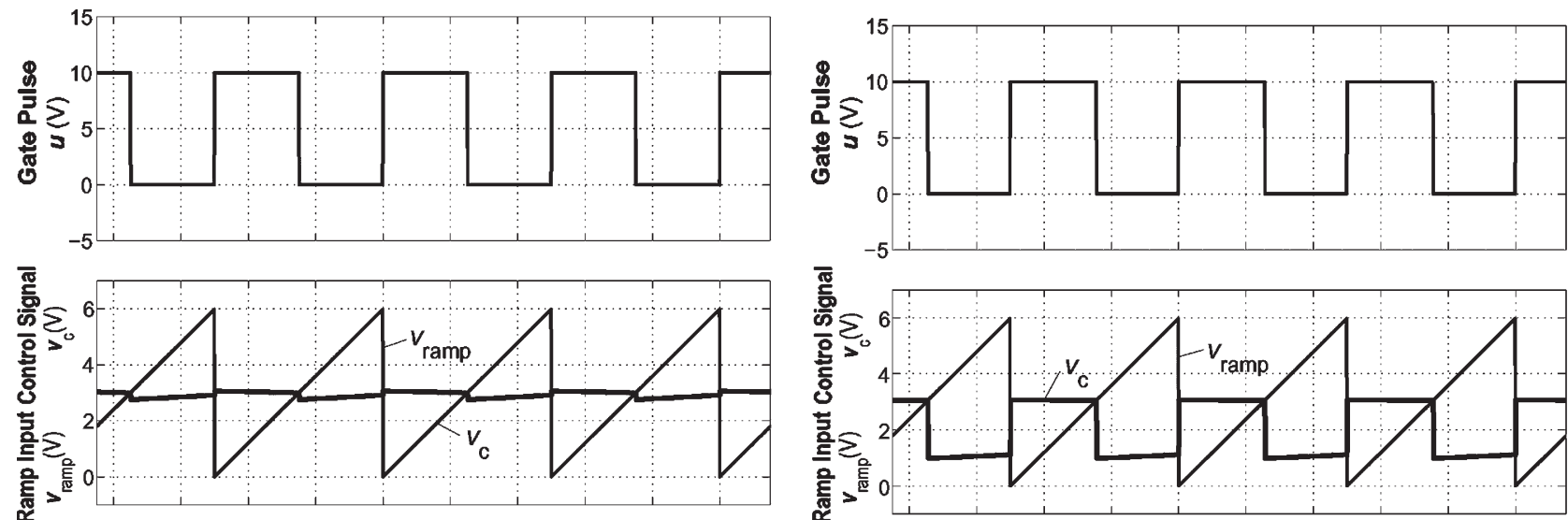

(a)

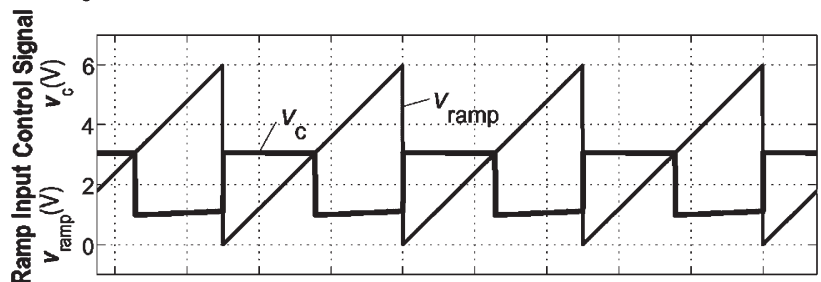

(b)

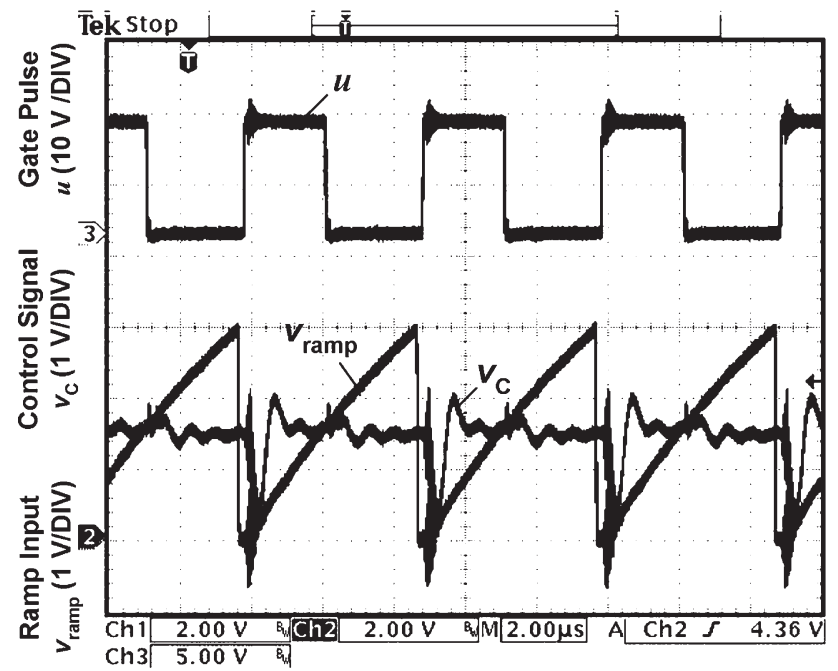

(c)

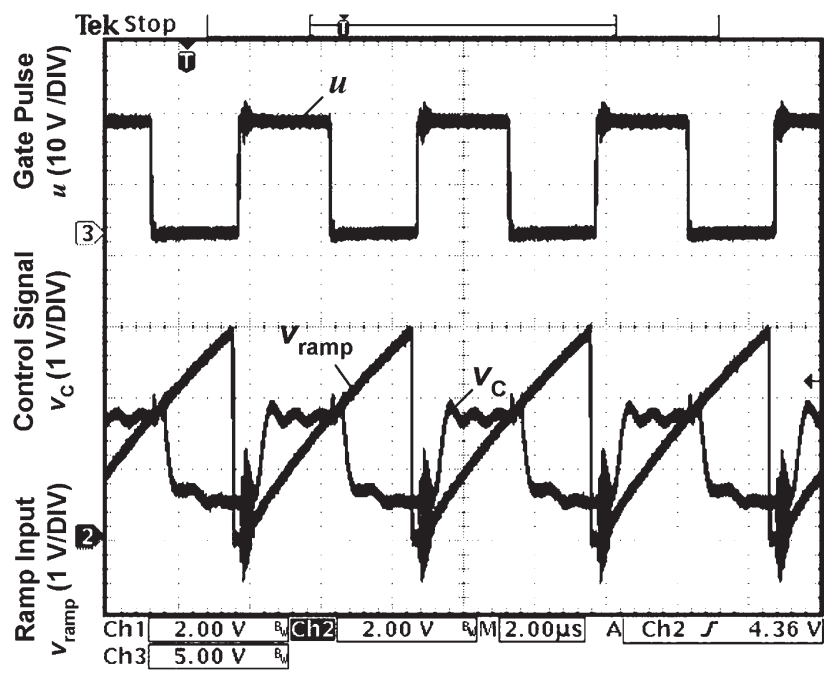

(d)

Fig. 5. Steady-state waveforms of control signal $v_{\mathrm{c}}$, input ramp $v_{\mathrm{ramp}}$, and generated gate pulse $u$ of the proposed SM-current-controlled boost converter operating at nominal input voltage $v_{\mathrm{i}}=24 \mathrm{~V}$. (a) Simulation results for minimum load: $r_{\mathrm{L}}=240 \Omega$. (b) Simulation results for maximum load: $r_{\mathrm{L}}=24 \Omega$. (c) Experimental results for minimum load: $r_{\mathrm{L}}=240 \Omega$. (d) Experimental results for maximum load: $r_{\mathrm{L}}=24 \Omega$.

TABLE III

Load-Regulation Property: Output Voltage at Nominal Operating Condition $v_{\mathrm{i}}=24 \mathrm{~V}$ AND $r_{\mathrm{L}}=24 \Omega$ IS $v_{\mathrm{o}(\text { nominal condition) }}=47.45 \mathrm{~V}$

\begin{tabular}{|c|c|c|}
\hline Input Voltage & Voltage Deviation: $\Delta v_{\mathrm{o}}=v_{\mathrm{o}(240 \Omega)}-v_{\mathrm{o}(24 \Omega)}$ & Percentage Change: $\frac{\Delta v_{\mathrm{o}}}{v_{\mathrm{o}(\text { nominal condition })}} \times 100 \%$ \\
\hline$v_{\mathrm{i}}=20 \mathrm{~V}$ & $1.13 \mathrm{~V}$ & $2.38 \%$ of $v_{\mathrm{o}(\text { nominal condition })}$ \\
\hline$v_{\mathrm{i}}=24 \mathrm{~V}$ & $0.82 \mathrm{~V}$ & $1.73 \%$ of $v_{\mathrm{o}(\text { nominal condition })}$ \\
\hline$v_{\mathrm{i}}=28 \mathrm{~V}$ & $0.35 \mathrm{~V}$ & $0.74 \%$ of $v_{\mathrm{o}(\text { nominal condition })}$ \\
\hline
\end{tabular}

TABLE IV

Line-Regulation Property: Output Voltage at Nominal Operating Condition $v_{i}=24 \mathrm{~V}$ AND $r_{L}=24 \Omega$ Is $v_{\mathrm{o}(\text { nominal condition) }}=47.45 \mathrm{~V}$

\begin{tabular}{|c|c|c|}
\hline Loading Condition & Voltage Deviation: $\Delta v_{\mathrm{o}}=v_{\mathrm{o}\left(\mathrm{v}_{\mathrm{i}}=20 \mathrm{~V}\right)}-v_{\mathrm{o}\left(\mathrm{v}_{\mathrm{i}}=28 \mathrm{~V}\right)}$ & Percentage Change: $\frac{\Delta v_{\mathrm{o}}}{v_{\mathrm{o}(\text { nominal condition })}} \times 100 \%$ \\
\hline Minimum load $(240 \Omega)$ & $0.40 \mathrm{~V}$ & $0.84 \%$ of $v_{\mathrm{o}(\text { nominal condition })}$ \\
\hline Half load $(48 \Omega)$ & $0.27 \mathrm{~V}$ & $0.57 \%$ of $v_{\mathrm{o}(\text { nominal condition })}$ \\
\hline Full load $(24 \Omega)$ & $0.14 \mathrm{~V}$ & $0.29 \%$ of $v_{\mathrm{o}(\text { nominal condition })}$ \\
\hline
\end{tabular}

Fig. 6(a)-(c) shows the experimental waveforms of the peak current-mode-controlled boost converter operating at a load resistance that alternates between $r_{\mathrm{L}}=24 \Omega$ and $r_{\mathrm{L}}=240 \Omega$ for various input voltages. The converter has been optimally tuned for the condition shown in Fig. 6(b). It can be observed that the dynamical behavior of the system is highly inconsistent with a different transient settling time for different operating condition. In the worst case operating condition: $v_{\mathrm{i}}=20 \mathrm{~V}$ and step-output current change of 0.2-2.0 A, the system has a settling time of $5.9 \mathrm{~ms}$ and a relatively high voltage ripple swing of $5.8 \mathrm{~V}$ [see Fig. 6(a)], which deviate greatly from the optimally designed value of $2 \mathrm{~ms}$ and a voltage ripple swing of $2.6 \mathrm{~V}$ [see Fig. 6(b)]. This large variation in the dynamical performances at various operating conditions is expected from the peak current-mode controller, which is seminonlinear, and its compensation network has been designed under a linearized 


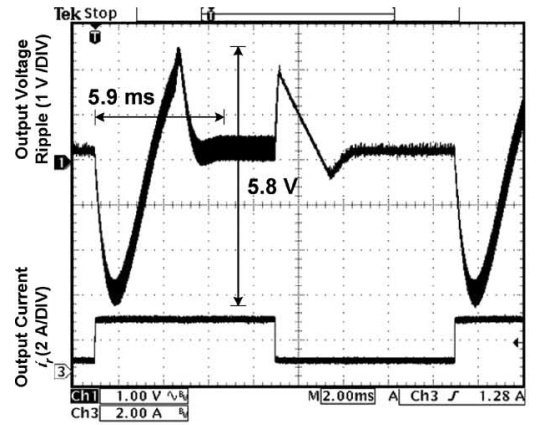

(a)

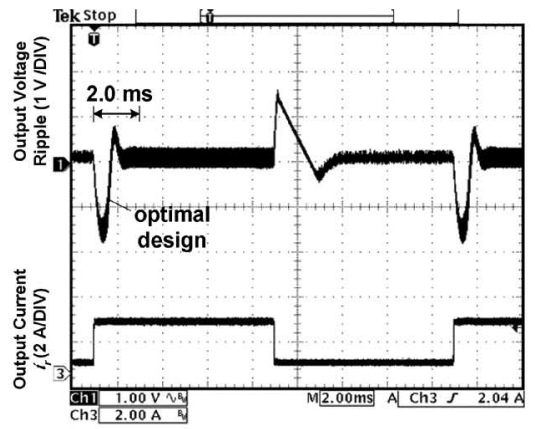

(b)

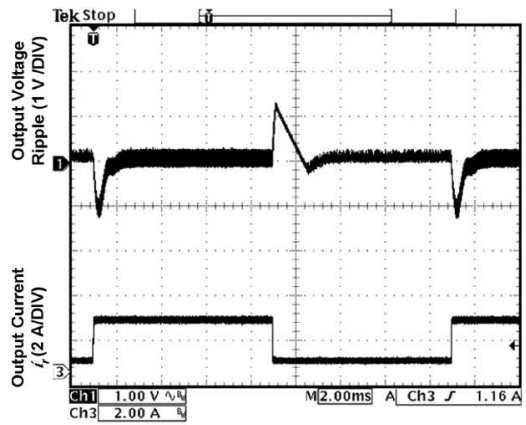

(c)

Fig. 6. Experimental waveforms of output-voltage ripple $\widetilde{v_{\mathrm{o}}}$ and output current $i_{\mathrm{r}}$ of the boost converter with the peak current-mode controller operating

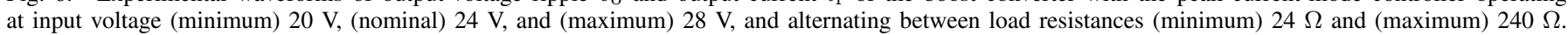
(a) $v_{\mathrm{i}}=20 \mathrm{~V}(0.2 / 2.0 \mathrm{~A})$. (b) $v_{\mathrm{i}}=24 \mathrm{~V}(0.2 / 2.0 \mathrm{~A})$. (c) $v_{\mathrm{i}}=28 \mathrm{~V}(0.2 / 2.0 \mathrm{~A})$.

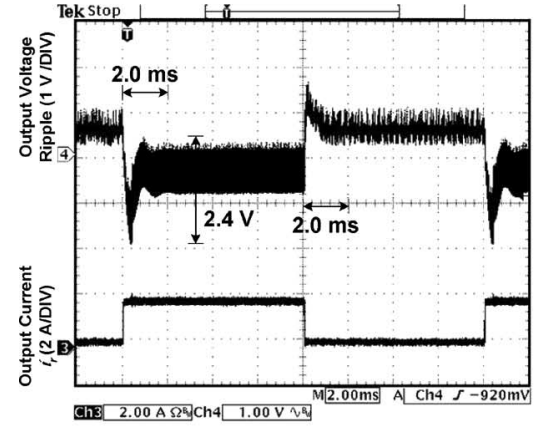

(a)

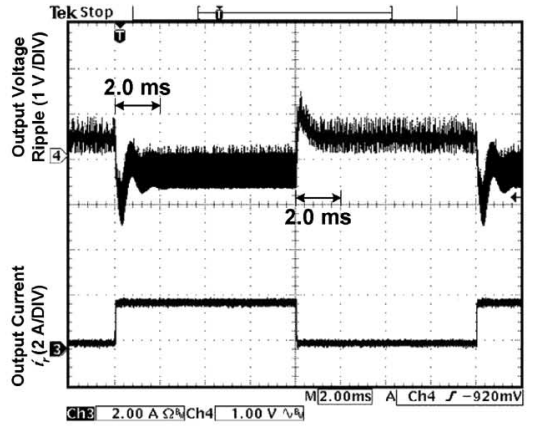

(b)

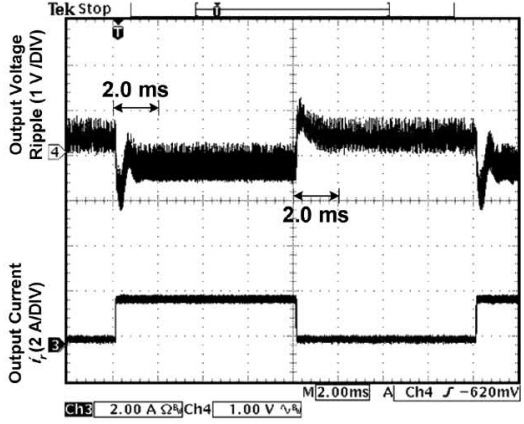

(c)

Fig. 7. Experimental waveforms of output voltage ripple $\widetilde{v_{\mathrm{o}}}$ and output current $i_{\mathrm{r}}$ of the boost converter with the proposed SM current-mode controller operating at an input voltage of (minimum) $20 \mathrm{~V}$, (nominal) $24 \mathrm{~V}$, and (maximum) $28 \mathrm{~V}$, and alternating between load resistances (minimum) $24 \Omega$ and (maximum) $240 \Omega$. (a) $v_{\mathrm{i}}=20 \mathrm{~V}(0.2 / 2.0 \mathrm{~A})$. (b) $v_{\mathrm{i}}=24 \mathrm{~V}(0.2 / 2.0 \mathrm{~A})$. (c) $v_{\mathrm{i}}=28 \mathrm{~V}(0.2 / 2.0 \mathrm{~A})$.

small-signal model that is only optimal for a specific operating condition.

Fig. 7(a)-(c) shows the dynamic behavior of the proposed SM-current-controlled boost converter at various input and load conditions. It can be seen that the transient settling time is around $2.0 \mathrm{~ms}$ for all operating conditions, including the worst case operating condition, which has a voltage ripple swing of around $2.4 \mathrm{~V}$ [see Fig. 7(a)]. This is close to the optimally designed point, which has a voltage ripple swing of $1.8 \mathrm{~V}$ [see Fig. 7(b)]. Comparing to the peak current-mode controller, which, in its worst case, has a settling time of $5.9 \mathrm{~ms}$ and a voltage ripple swing of $5.8 \mathrm{~V}$, the advantage of the proposed SM current-mode controller in giving a fast and consistent dynamical response over a wide range of operating conditions is distinctively demonstrated.

On the other hand, the output voltage ripple of the boost converter is higher with the proposed SM-current controller than the peak current-mode controller. The higher voltage ripple is caused by the impedance of the additional current sensor CS 1100 located at the output-capacitor-filter path in the proposed scheme. Typically, it can be reduced using a current sensor of lower impedance. Otherwise, if required, the indirect sensing of the capacitor current, which totally removes the requirement for the capacitor-current sensor, will restore the voltage ripple back to its original state. There are two methods of doing this. One method is by first sensing the inductor current and then extracting the ac component of the turn-off (i.e., $1-D$ ) period of the inductor-current signal. This operation will produce an information that is identical to that of the capacitor-current signal. The disadvantage of using this method is the requirement of an additional circuitry for processing the information. On the other hand, capacitor current can also be obtained by performing a derivative of the output voltage. This will also provide the capacitor-current information. However, such operation requires careful noise filtering of the signal since differentiators are highly noise sensitive and may distort the required information.

\section{CONCLUSiON}

A fast-response SM current controller that operates at a fixed frequency is proposed for boost-type converters. The various aspects of the controller, which includes the method of generating the reference current profile, the choice of sliding surface, the existence and stability properties, and the selection of the control parameters, are discussed in the paper. It is experimentally demonstrated that, with the proposed controller, the boost converter has a faster response with a lower voltage overshoot over a wide range of operating conditions than the peak current-mode controller. It can therefore be concluded that the proposed SM current controller may be a good alternative over conventional current-mode controllers for fast-response boost-converter applications but at a higher implementation cost and circuit complexity. 


\section{REFERENCES}

[1] F. A. Himmelstoss, J. W. Kolar, and F. C. Zach, "Analysis of a smithpredictor-based-control concept eliminating the right-half plane zero of continuous mode boost and buck-boost DC/DC converters," in Proc. Int. Conf. IECON, Nov. 1991, pp. 423-428.

[2] R. Ridley, "Current mode or voltage mode?" Switching Power Mag., pp. 4-9, Oct. 2000.

[3] R. Mammano, Switching Power Supply Topology: Voltage Mode Versus Current Mode, Jun. 1994. Unitrode Design Note.

[4] C. K. Tse and K. M. Adams, "An adaptive control for DC-DC converters," in Proc. IEEE PESC, Jun. 1990, pp. 213-218.

[5] E. Figueres, G. Garcera, J. M. Benavent, M. Pascual, and J. A. Martinez, "Adaptive two-loop voltage-mode control of DC-DC switching converters," IEEE Trans. Ind. Electron., vol. 53, no. 1, pp. 239-253, Feb. 2006.

[6] W. C. So, C. K. Tse, and Y. S. Lee, "Development of a fuzzy logic controller for DC/DC converters: Design, computer simulation and experimental evaluation," IEEE Trans. Power Electron., vol. 11, no. 1, pp. 2432, Jan. 1996.

[7] P. Mattavelli, L. Rossetto, G. Spiazzi, and P. Tenti, "General purpose fuzzy controller for DC-DC converters," IEEE Trans. Power Electron., vol. 12, no. 1, pp. 79-86, Jan. 1997.

[8] A. Ofoli and A. Rubaai, "Real-time implementation of a fuzzy logic controller for switch-mode power-stage DC-DC converters," IEEE Trans. Ind. Appl., vol. 42, no. 6, pp. 1367-1374, Nov./Dec. 2006.

[9] K. H. Cheng, C. F. Hsu, C. M. Lin, T. T. Lee, and C. Li, "Fuzzyneural sliding-mode control for DC-DC converters using asymmetric Gaussian membership functions," IEEE Trans. Ind. Electron., vol. 54, no. 3, pp. 1528-1536, Jun. 2007.

[10] K. Viswanathan, R. Oruganti, and D. Srinivasan, "Nonlinear function controller: A simple alternative to fuzzy logic controller for a power electronic converter," IEEE Trans. Ind. Electron., vol. 52, no. 5, pp. 1439-1448, Oct. 2005

[11] C. Y. Chan, "A nonlinear control for DC-DC power converters," IEEE Trans. Power Electron., vol. 22, no. 1, pp. 216-222, Jan. 2007.

[12] H. C. Chan, K. T. Chau Adams, and C. C. Chan, "A neural network controller for switching power converters," in Proc. IEEE PESC, 1993, pp. 887-892.

[13] K. M. Smedley and S. Ćuk, "One-cycle control of switching converters," IEEE Trans. Power Electron., vol. 10, no. 6, pp. 625-633, Nov. 1995.

[14] R. Venkataramanan, A. Sabanoivc, and S. Cuk, "Sliding mode control of DC-to-DC converters," in Proc. IEEE IECON, 1985, pp. 251-258.

[15] P. Mattavelli, L. Rossetto, G. Spiazzi, and P. Tenti, "General-purpose sliding-mode controller for DC/DC converter applications," in Proc. IEEE PESC, Jun. 1993, pp. 609-615.

[16] D. Cortes and J. Alvarez, "Robust sliding mode control for the boost converter," in Proc. IEEE Conf. Power Electron. Congr., Oct. 2002, pp. 208-212.

[17] E. Vidal-Idiarte, L. Martinez-Salamero, F. Guinjoan, J. Calvente, and S. Gomariz, "Sliding and fuzzy control of a boost converter using an 8-bit microcontroller," Proc. Inst. Electr. Eng.-Electric Power Applications, vol. 151, no. 1, pp. 5-11, Jan. 2004.

[18] M. Castilla, L. G. de Vicuna, J. M. Guerrero, J. Matas, and J. Miret, "Sliding-mode control of quantum series-parallel resonant converters via input-output linearization," IEEE Trans. Ind. Electron., vol. 52, no. 2, pp. 566-575, Apr. 2005.

[19] P. Gupta and A. Patra, "Hybrid mode-switched control of DC-DC boost converter circuits," IEEE Trans. Circuits Syst. II, Exp. Briefs, vol. 52, no. 11, pp. 734-738, Nov. 2005.

[20] E. Vidal-Idiarte, L. Martinez-Salamero, J. Calvente, and A. Romero, "An $H_{\infty}$ control strategy for switching converters in sliding-mode current control," IEEE Trans. Power Electron., vol. 21, no. 2, pp. 553-556, Mar. 2006.

[21] S. C. Tan, Y. M. Lai, and C. K. Tse, "Implementation of pulse-widthmodulation based sliding mode controller for boost converters," IEEE Power Electron. Lett., vol. 3, no. 4, pp. 130-135, Dec. 2005.

[22] B. J. Cardoso, A. F. Moreira, B. R. Menezes, and P. C. Cortizo, "Analysis of switching frequency reduction methods applied to sliding mode controlled DC-DC converters," in Proc. IEEE APEC, Feb. 1992, pp. 403-410.

[23] L. Malesani, L. Rossetto, G. Spiazzi, and P. Tenti, "Performance optimization of Cuk converters by sliding-mode control," IEEE Trans. Power Electron., vol. 10, no. 3, pp. 302-309, May 1995.

[24] V. M. Nguyen and C. Q. Lee, "Tracking control of buck converter using sliding-mode with adaptive hysteresis," in Proc. IEEE PESC, Jun. 1995, vol. 2, pp. 1086-1093.
[25] P. Mattavelli, L. Rossetto, and G. Spiazzi, "Small-signal analysis of DC-DC converters with sliding mode control," IEEE Trans. Power Electron., vol. 12, no. 1, pp. 96-102, Jan. 1997.

[26] M. Castilla, L. C. de Vicuna, M. Lopez, O. Lopez, and J. Matas, "On the design of sliding mode control schemes for quantum resonant converters," IEEE Trans. Power Electron., vol. 15, no. 15, pp. 960-973, Nov. 2000.

[27] S. C. Tan, Y. M. Lai, C. K. Tse, and M. K. H. Cheung, "Adaptive feedforward and feedback control schemes for sliding mode controlled power converters," IEEE Trans. Power Electron., vol. 21, no. 1, pp. 182-192, Jan. 2000.

[28] V. M. Nguyen and C. Q. Lee, "Indirect implementations of sliding-mode control law in buck-type converters," in Proc. IEEE APEC, Mar. 1996, vol. 1, pp. 111-115.

[29] J. Mahdavi, A. Emadi, and H. A. Toliyat, "Application of state space averaging method to sliding mode control of PWM DC/DC converters," in Proc. IEEE Conf. IAS, Oct. 1997, vol. 2, pp. 820-827.

[30] C. C. Wu and C. M. Young, "A new PWM control strategy for the buck converter," in Proc. IEEE IECON, 1999, pp. 157-162.

[31] J. Mahdavi, M. R. Nasiri, A. Agah, and A. Emadi, "Application of neural networks and state space averaging to a DC/DC PWM converter in sliding-mode operation," IEEE/ASME Trans. Mechatronics, vol. 10, no. 1, pp. 60-67, Feb. 2005.

[32] S. C. Tan, Y. M. Lai, C. K Tse, and M. K. H. Cheung, "A fixed-frequency pulse-width-modulation based quasi-sliding mode controller for buck converters," IEEE Trans. Power Electron., vol. 20, no. 6, pp. 1379-1392, Nov. 2005.

[33] Y. He and F. L. Luo, "Sliding-mode control for DC-DC converters with constant switching frequency," Proc. Inst. Electr. Eng.-Control Theory and Applications, vol. 153, no. 1, pp. 37-45, Jan. 2006.

[34] Y. He and F. L. Luo, "Design and analysis of adaptive sliding-modelike controller for DC-DC converters," Proc. Inst. Electr. Eng.-Electric Power Applications, vol. 153, no. 3, pp. 401-410, May 2006.

[35] S. C. Tan, Y. M. Lai, and C. K. Tse, "A unified approach to the design of PWM based sliding mode voltage controller for basic DC-DC converters in continuous conduction mode," IEEE Trans. Circuits Syst. I, Reg. Papers, vol. 53, no. 8, pp. 1816-1827, Aug. 2006.

[36] S. C. Tan, Y. M. Lai, C. K. Tse, and L. Martinez-Salamero, "Special family of PWM-based sliding mode voltage controllers for basic DC-DC converters in discontinuous conduction mode," IET Elect. Power Appl., vol. 1, no. 1, pp. 64-74, Jan. 2007.

[37] V. Utkin, J. Guldner, and J. X. Shi, Sliding Mode Control in Electromechanical Systems. London, U.K.: Taylor \& Francis, 1999.

[38] G. Escobar, R. Ortega, H. Sira-Ramirez, J. P. Vilain, and I. Zein, "An experimental comparison of several nonlinear controllers for power converters," IEEE Control Syst. Mag., vol. 19, no. 1, pp. 66-82, Feb. 1999.

[39] S. K. Mazumder, A. H. Nayfeh, and D. Borojević, "Robust control of parallel DC-DC buck converters by combining integral-variable-structure and multiple-sliding-surface control schemes," IEEE Trans. Power Electron., vol. 17, no. 3, pp. 428-437, May 2002.

[40] H. Sira-Ramirez, "On the generalized PI sliding mode control of DCto-DC power converters: A tutorial," Int. J. Control, vol. 76, no. 9/10, pp. 1018-1033, 2003.

[41] E. Fossas, L. Martínez, and J. Ordinas, "Sliding mode control reduces audiosusceptibility and load perturbation in the Ćuk converter," IEEE Trans. Circuits Syst. I, Reg. Papers, vol. 39, no. 10, pp. 847-849, Oct. 1992.

[42] L. Martinez-Salamero, J. Calvente, R. Giral, A. Poveda, and E. Fossas, "Analysis of a bidirectional coupled-inductor Ćuk converter operating in sliding mode," IEEE Trans. Circuits Syst. I, Fundam. Theory Appl., vol. 45, no. 4, pp. 355-363, Apr. 1998.

[43] L. Martinez-Salamero, H. Valderrama-Blavi, and R. Giral, "Selfoscillating DC-to-DC switching converters with transformers characteristics," IEEE Trans. Aerosp. Electron. Syst., vol. 41, no. 2, pp. 710-716, Apr. 2005.

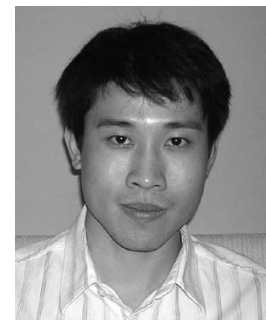

Siew-Chong Tan (S'01-M'05) received the B.Eng. (with honors) and M.Eng. degrees in electrical and computer engineering from the National University of Singapore, Singapore, in 2000 and 2002, respectively, and the Ph.D. degree from Hong Kong Polytechnic University, Kowloon, Hong Kong, in 2005.

He was, briefly, a Research Associate and, then, a Postdoctoral Fellow with the Department of Electronic and Information Engineering, Hong Kong Polytechnic University, where he is currently a Lecturer. His research interests include motor drives and power electronics. 


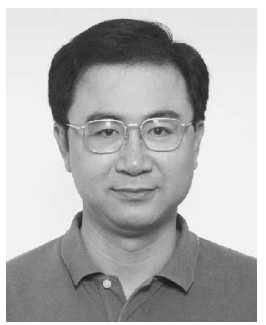

Y. M. Lai (M'92) received the B.Eng. degree in electrical engineering from the University of Western Australia, Perth, Australia, in 1983, the M.Eng.Sc. degree in electrical engineering from the University of Sydney, Sydney, Australia, in 1986, and the Ph.D. degree from Brunel University, Uxbridge, U.K., in 1997.

He is currently an Assistant Professor with Hong Kong Polytechnic University, Kowloon, Hong Kong. His research interests include computer-aided design of power electronics and nonlinear dynamics.

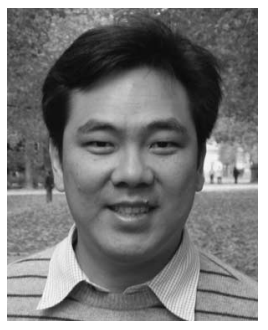

Chi K. Tse (M'90-SM'97-F'06) received the B.Eng. degree (with first class honors) in electrical engineering and the $\mathrm{Ph} . \mathrm{D}$. degree from the University of Melbourne, Melbourne, Australia, in 1987 and 1991, respectively.

$\mathrm{He}$ is currently a Chair Professor and the Head of the Department of Electronic and Information Engineering, Hong Kong Polytechnic University, Kowloon, Hong Kong. He is also a Guest Professor of Wuhan University, Wuhan, China, and of Southwest University, Chongqing, China. His research interests include power electronics, complex networks, and nonlinear systems. He is the author of Linear Circuit Analysis (London, U.K.: Addison-Wesley 1998) and Complex Behavior of Switching Power Converters (Boca Raton: CRC Press, 2003), coauthor of Chaos-Based Digital Communication Systems (Heidelberg, Germany: Springer-Verlag, 2003) and Chaotic Signal Reconstruction with Applications to Chaos-Based Communications (Beijing: TUP, 2005). $\mathrm{He}$ is the coholder of a U.S. patent with two patents pending.

Dr. Tse was the recipient of the L. R. East Prize by the Institution of Engineers, Australia, in 1987, the IEEE TRANS ACTIONS ON POWER ElECTRONICS Prize Paper Award in 2001, and the International Journal of Circuit Theory and Applications Best Paper Award in 2003. He was the recipient of the Distinguished International Research Fellowship by the University of Calgary, Calgary, Canada, in 2007. While he was with the Hong Kong Polytechnic University, he was twice the recipient of the President's Award for Achievement in Research, the Faculty's Best Researcher Award, the Research Grant Achievement Award, and a few other teaching awards. From 1999 to 2001, he was an Associate Editor for the IEEE TRANSACTIONS ON CIRCUITS AND Systems PART I-FundAMENTAL THEORY AND APPLICATIONS, and since 1999, he has been an Associate Editor for the IEEE TRANSACTIONS ON POWER ELECTRONICS. In 2005, he served as an IEEE Distinguished Lecturer. $\mathrm{He}$ is also currently serving as the Editor-in-Chief of the IEEE Circuits and Systems Society Newsletter, as an Associate Editor for the International Journal of Systems Science, and as a Guest Editor of a few other journals.

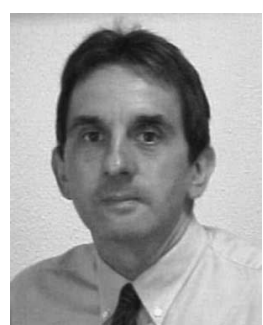

Luis Martínez-Salamero (M'79-SM'86) received the Ingeniero de Telecomunicación and Doctorate degrees from the Universidad Politécnica de Cataluña, Barcelona, Spain, in 1978 and 1984, respectively.

From 1978 to 1992 , he taught circuit theory, analog electronics, and power processing with the Escuela Técnica Superior de Ingenieros de Telecomunicación de Barcelona, Barcelona. From 1992 to 1993, he was a Visiting Professor with the Center for Solid-State Power Conditioning and Control, Department of Electrical Engineering, Duke University, Durham, NC. From 2003 to 2004, he was a Visiting Scholar with the Laboratoire d' Architecture et d'Analyse des Systémes, Research National Center, Toulouse, France. He is currently a Full Professor with the Departamento de Ingeniería Eléctrónica, Eléctrica y Automática, Escuela Técnica Superior de Ingeniería, Universidad Rovira i Virgili, Tarragona, Spain. His research interests are in the field of structure and control of power conditioning systems for autonomous systems. He has published a great number of papers in scientific journals and conference proceedings and is the holder of a U.S. patent on the electric-energy distribution in vehicles by means of a bidirectional dc-to-dc switching converter. He is the Director of the Grupo de Automática y Electrónica Industrial, a research group on Industrial Electronics and Automatic Control whose main research fields are in power conditioning for vehicles, satellites, and renewable energy.

Dr. Martínez-Salamero was a Guest Editor of the IEEE TRANSACTIONS Circuits AND Systems-I: Fundamental Theory AND APPLiCATIONS (vol. 44, no. 8, August 1997) for the Special Issue on Simulation, Theory, and Design of Switched-Analog Networks. He has been a Distinguished Lecturer of the IEEE Circuits and Systems Society from 2001 to 2002. He is currently the President of the Spanish Chapter of the IEEE Power Electronics Society.

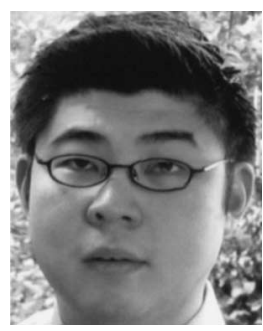

Chi-Kin Wu received the B.Eng. degree (with honors) in electrical and information engineering from Hong Kong Polytechnic University, Kowloon, Hong Kong, in 2005.

From 2002 to 2005, he was a power electronics engineer with Newton Power Company Ltd., Hong Kong. Since 2005, he has been a Research/Teaching Assistant with Hong Kong Polytechnic University. His research interests include switching-mode power supply and converter designs. 